University of Wollongong

Research Online

Faculty of Law, Humanities and the Arts Papers (Archive)

Faculty of Arts, Social Sciences \& Humanities

$1-1-2012$

The body in social context: some qualifications on the "warmth and intimacy" of bodily self-consciousness

Shaun Gallagher

University of Memphis

Follow this and additional works at: https://ro.uow.edu.au/lhapapers

Part of the Arts and Humanities Commons, and the Law Commons

Research Online is the open access institutional repository for the University of Wollongong. For further information contact the UOW Library: research-pubs@uow.edu.au 


\title{
The body in social context: some qualifications on the "warmth and intimacy" of bodily self-consciousness
}

\begin{abstract}
In this paper I examine William James' concept of the 'warmth and intimacy' of bodily self-consciousness and relate it to recent attempts to recast bodily self-consciousness in strictly neural terms. James takes bodily 'warmth and intimacy' to solve a number of problems related to the material and spiritual aspects of self and personal identity. He mentions but does not fully explore the possible disruptions in the bodily sense of ownership that can come about as the result of experimental and pathological circumstances, and that would have to qualify such solutions. I argue that an explanation in strictly neuroscientific terms does no better in accounting for bodily self-consciousness. Both James and proponents of the 'body-inthe-brain' theory ignore the social aspects of the self and the role they play in accounting for bodily selfconsciousness and its various disruptions.
\end{abstract}

\section{Keywords}

social, consciousness, body, self, bodily, intimacy, warmth, qualifications, context

\section{Disciplines}

Arts and Humanities | Law

\section{Publication Details}

Gallagher, S. 2012, 'The body in social context: some qualifications on the "warmth and intimacy" of bodily self-consciousness', Grazer Philosophische Studien: internationale Zeitschrift fuer analytische Philosophie, vol. 84, pp. 91-121. 


\title{
THE BODY IN SOCIAL CONTEXT: \\ SOME QUALIFICATIONS ON THE 'WARMTH AND INTIMACY’ OF BODILY SELF-CONSCIOUSNESS ${ }^{1}$
}

\author{
Shaun GALLAGHER \\ University of Memphis
}

\begin{abstract}
Summary
In this paper I examine William James' concept of the 'warmth and intimacy' of bodily self-consciousness and relate it to recent attempts to recast bodily selfconsciousness in strictly neural terms. James takes bodily 'warmth and intimacy' to solve a number of problems related to the material and spiritual aspects of self and personal identity. He mentions but does not fully explore the possible disruptions in the bodily sense of ownership that can come about as the result of experimental and pathological circumstances, and that would have to qualify such solutions. I argue that an explanation in strictly neuroscientific terms does no better in accounting for bodily self-consciousness. Both James and proponents of the 'body-in-the-brain' theory ignore the social aspects of the self and the role they play in accounting for bodily self-consciousness and its various disruptions.
\end{abstract}

My awareness of my body, when, as in most cases, it is accompanied by a sense of ownership, that is, a sense that this body is my body, is a form of self-consciousness. ${ }^{2}$ In this regard, the body consciously appears, not as a perceived object external to the self over which one claims ownership, but

1. This paper was motivated by a discussion I had in November 2009 with my friend John Michael Krois at Humboldt University and on a walk in the nearby areas of Berlin which included a visit to the building where William James stayed while in that city. John died unexpectedly and too young in the Fall of 2010. I dedicate this paper to his memory. An earlier version of this paper was presented at the Meaning and Mindedness public lecture series at the Travistock Clinic, University of London in March 2011. I've also benefited from comments by Anthony J. Marcel, Frederique de Vignemont and Glenn Carruthers on an earlier draft.

2. I employ a certain looseness of terminology throughout this paper in regard to the notion of awareness or consciousness of one's own body. Rather than using an abbreviation to attain a precision that may not reflect the kind of ambiguous phenomenon under discussion, I prefer to stay with a set of what I take here to be more or less equivalent phrases: 'self-consciousness of one's body,' 'bodily self-consciousness', 'bodily self-awareness'. 
rather, pre-reflectively, as the perceiving subject or agent that I am. William James (1890) called this an aspect of the "material Self." This kind of selfconsciousness seems unproblematic for James. I say this for two reasons. First, he no sooner introduces the idea than he abandons discussion of it and moves on to talk about other aspects of the material self, such as the clothes that we wear. Indeed, he devotes only one-half sentence to it in his chapter on "The Consciousness of Self" in his Principles of Psychology: "certain parts of the body seem more intimately ours than the rest" (292). If this is a problem, he does not come back to it as such. Second, to put this most precisely, when he does come back to this idea, he comes back to it, not as a problem, but as a solution, and as a way to deflate the concept of the spiritual self. After doing a bit of phenomenological description of the stream of experience, he comes to the idea that the central core of this spiritual self is something felt, and it is just here that the body comes back on the scene. The central nucleus of the self is felt, "just as the body is felt" (299). Which means, for James, that it is felt as an abstraction.

What James means by saying that the body is felt as an abstraction is, curiously, just the opposite of what we might think. He means that it is never felt as an abstraction: the self is felt, "just as the body is felt, the feeling of which is also an abstraction, because never is the body felt all alone, but always together with other things" (299). James' claim, however, is stronger than simply positing an analogy between the feeling of the body and the feeling of the self. Rather, the former is the solution to the question, "What do we feel (i.e., experience) when we feel the central nucleus of the spiritual self?" His answer is that we feel the body. "Whenever my introspective glance succeeds in turning round quickly enough to catch one of these manifestations of spontaneity in the act, all it can ever feel distinctly is some bodily process, for the most part taking place within the head" (300). 'Within the head' does not mean 'in the brain', but instead physical movements in and of the head. He goes into some details about eye movements that accompany the thinking and visualizing of things in the stream of consciousness, movements of the mechanisms of throat, mouth, and jaw-muscles, of the brow, etc., which then give way to feelings connected with "many body parts" and the body as a "larger mass." This solution is repeated numerous times under the heading of "the feeling of warmth and intimacy," which is the feeling of the body. This frames his solution to the problem of personal identity, for example. Our thoughts, as they stream along, are felt "with warmth and intimacy." 
Of course this is the case with the bodily part of it; we feel the whole cubic mass of our body all the while, it gives us an unceasing sense of personal existence. Equally do we feel the inner 'nucleus of the spiritual self,' either in the shape of yon faint physiological adjustments, or (adopting the universal psychological belief), in that of the pure activity of our thought taking place as such. Our remoter spiritual, material, and social selves, so far as they are realized, come also with a glow and a warmth; for the thought of them infallibly brings some degree of organic emotion in the shape of quickened heart-beats, oppressed breathing, or some other alteration, even though it be a slight one, in the general bodily tone. The character of 'warmth,' then, in the present self, reduces itself to either of two things, - something in the feeling which we have of the thought itself, as thinking, or else the feeling of the body's actual existence at the moment, - or finally to both. We cannot realize our present self without simultaneously feeling one or other of these two things. Any other fact which brings these two things with it into consciousness will be thought with a warmth and an intimacy like those which cling to the present self. (333)

The parentheses that mark "the universal psychological belief" signal a doubt that James has about the concept of the "pure activity of our thought"; the parentheses appear again (this time with a question mark) later in the text: "A uniform feeling of 'warmth', of bodily existence (or an equally uniform feeling of pure psychic energy?) pervades [all self experience]" (335). What James knows for sure is that the feelings of warmth and intimacy that belong to the self are bodily in nature.

In recent philosophy and science, in contexts that still involve questions about self and self-consciousness, but in contrast to James, this feeling or experience of the body is itself taken to be the locus of a set of problems rather than a solution to other problems. In this paper I discuss the problems associated with the self-awareness of the body, to see how they complicate the issues that James thought were solved by this experience. My strategy is to review some recent research on the concepts of body image and body schema that explores issues pertaining to the awareness of one's own body. The qualifications on 'warmth and intimacy' that I want to introduce come by way of looking at some pathological disorders that involve bodily self-awareness. The idea is not simply that things can go wrong with bodily self-awareness — surely something that James was knowledgeable about-but that bodily self-awareness, no less than other aspects of the material self, is not a mere private or personal aspect of the self, but is already permeated by intersubjective or social dimensions. In 
James' terms, the social self is not as "remote" from bodily self-awareness as James may have thought.

\section{Body image and body schema}

We need a way to think about the role that the body (or embodiment) plays in consciousness and cognition, and we need a way to think about pathologies that affect embodiment-including those that disrupt movement, action, and agency as well as bodily self-awareness, the sense of ownership for one's body and one's action, and self-identity. I have defended the rather contentious idea that the concepts of body image and body schema, if properly distinguished, while not the basis for a complete explanation, can still do some useful work in this regard (Gallagher 2005). The historical imprecision and lack of clarity associated with these concepts, however, have motivated some (e.g., Straus 1967; Poeck and Orgass 1971; Spicker, 1975; Critchley 1979) to suggest alternative approaches, and even to abandon these concepts. One alternative suggestion is that the best way to approach questions about bodily self-awareness and the role of the body in pathological and non-pathological experience is to focus on 'the body in the brain' (Berlucchi and Aglioti 1997; 2010). That is, the alternative strategy is to frame the discussion in terms of the neural correlates of the various aspects of self-awareness, agency, ownership, self-identity, etc. My intention is not to dismiss this strategy, which I think provides important and essential knowledge about how bodily experience works and breaks down; rather my intention is to argue (1) that this strategy also has its problems insofar as we still run into complex ambiguities when it comes to mapping out brain function, and (2) that this strategy is not sufficient in itself, even if such ambiguities can be resolved. In this regard I want to point to an overlooked virtue to be found in the concepts of body image and body schema - a virtue overlooked and entirely underexploited to such an extent that, as I present it, it may look as if I'm introducing something completely different into the discussion.

What is often overlooked and underexploited in regard to body image/ body schema is the intersubjective or social aspect implicit in these phenomena and in embodied experience generally. Moreover, in the alternative proposal that looks for the body in the brain, what is almost always neglected is the way the body is dynamically coupled to an environment that is primarily a social environment. The idea, then, is that body image 
and body schema are not just an individual subject's representations of his or her individual body, which may then come to be related to others that we encounter in the environment, but that body image and body schema are constitutionally referenced to others and are implicitly intersubjective.

It will be best to start with a characterization of the conceptual distinction between body image and body schema. This, at least, is the one I defend (Gallagher 2005), and the one that is under discussion in a number of recent theoretical and experimental papers, some of which I mention below. A body image consists of a system of perceptions, attitudes, and beliefs pertaining to one's own body. In contrast, a body schema is a system of sensory-motor capacities that function normally without awareness or the necessity of perceptual monitoring that takes the body as an object. The difference is one between having a perception of (or belief about) something and having a capacity to move (or an ability to do something). Body image is not limited to occurrent perceptions. It includes beliefs about the body and attitudes towards the body. In contrast, the body schema involves motor control processes, motor capacities, abilities, and habits that both enable and constrain movement and the maintenance of posture. The body schema continues to operate, and in many cases operates best, when the intentional object of perception is something other than one's own body.

This conceptual distinction is just that, a conceptual distinction. In this respect, it's necessary to point out two things. First, that in our normal everyday behavior and action, body image and body schema interact in an integrated manner and are difficult to distinguish, both phenomenologically and neurologically (Gallagher 2005; Kammers 2008)—it may be the case, for example, that we rely on both in the learning of a new movement, and/or that there is some overlap in brain processes that are related to both body image and body schema. Second, the distinction may be helpful in explaining some aspects of movement and motor control, body awareness, and certain related pathologies, but it is not meant as a complete explanation. The idea that it may be helpful to understand a problem as one involving the body schema rather than the body image, for example, may mean simply that in explaining or addressing the problem, the distinction may point us to different neurological or psychological factors. Let me also note here (and see below) that this distinction cuts across the conscious vs non-conscious distinction; while most aspects of body image can be, or can be made conscious, not all aspects are always conscious. And while most aspects of body-schematic processes are non-conscious, this does not 
rule out the possibility that such processes may generate a pre-reflective form of body awareness, or that we may become more explicitly aware of some aspects of how our body is moving. For example, if during a game, I am chasing a ball, I am likely aware of my bodily movement and that I am moving fast enough or not fast enough to catch the ball. This does not entail an explicit or detailed consciousness of body-schematic processes such as the controlled dynamics of my leg movements although, in part, it may those controlled dynamics that generate the a sense of effort and speed that I feel.

Over the years, as I mentioned, there have been various calls to abandon the these concepts. In the latest version of this critique, Berlucchi and Aglioti (2010) focus on some problems involved in the awareness of one's body. They note the confused history and terminological wars associated with the concepts of body image and body schema, and they begin with the distinction as defined above, and as it is proposed by Paillard (1999) and in my own work (Gallagher 1986; 2005).

Both Paillard and I appeal to double dissociations to indicate empirical support for the distinction. Thus, for example, in certain cases of unilateral neglect, stroke victims who do not notice or acknowledge the left side of their bodies, still employ the left hand to do certain things (such as dressing), and their left leg to walk. This is a case where there are severe body image problems, but intact body schema. The other side of the dissociation can be seen in deafferented patients such as IW (Gallagher and Cole 1996) who, because of the loss of proprioception and the tactile modality below the neck, must use conscious visual monitoring to control their movement. In this case, we have a severe deficiency in body schematic processes, and an enhanced, vision-based body image taking over aspects of motor control usually accomplished by those processes (Gallagher 2005). ${ }^{3}$

3. Vignemont (2010) challenges this particular interpretation. She suggests that deafferented subjects still have an intact body schema, except that it is guided by vision instead of proprioception. But if non-conscious visual perception (something that certainly can contribute to body-schematic processes) should count as part of a body image, as Vignemont suggests in the case of unilateral neglect, it's not clear why conscious visual perception (which deafferented agents need to guide their movement) would not count as part of body image. The issue here, and more generally, is not what sensory inputs are involved (vision versus proprioception), but how much non-automatic, and often thoughtful, attentive control (using the body image) is required. In this regard, Vignemont is clearly incorrect when she suggests that deafferented patients like IW or GL are like "automatic drivers" whose actions become automatic routines after significant practice. Although some aspects of gait seem close to automatic in IW, in all other regards he is unable to form motor programs or motor habits that would allow him to walk or reach or grasp, etc. automatically (or close to automatically), i.e., without consciously 
As pointed out by Vignemont (2010), one can find a similar dissociation between body image and body schema in the rubber hand illusion where there is a proprioceptive drift toward the rubber hand for the perceptual response in judging where one's hidden hand is, but no proprioceptive drift for the motor responses when one is asked to reach to touch one's hand without vision (Kammers et al. 2009). ${ }^{4}$ Further empirical support is provided by Dijkerman and de Haan (2007; also see Anema et al. 2009) who show that there are two partly divided anatomical and functional systems: one responsible for the immediate and automatic guidance of action, centered in the posterior parietal cortex, and the other responsible for conscious body perception centered in the insula. As Berlucchi and Aglioti (2010) note, however, this is not an absolutely clean neurological independence. Just like the two-pathway visual processing systems proposed by Milner and Goodale (1995), there are various ways in which these systems integrate. Thus, processes in the posterior parietal cortex, different from those that guide action may also be involved in high-level visuo-spatial and semantic consciousness of the body; and we know from other studies, that the insula is involved in sensory integration and motor control processes (Farrer and Frith 2003; Farrer et al. 2003).

With respect to the issue of body awareness, it's important to point out that although there is an obvious involvement of the body image, which may involve conscious perception of the body, but also beliefs and

thinking about what he is doing and monitoring his movement and posture. Clearly, the need for this attentive monitoring is what a body schema eliminates.

4. See Kammers et al. (2010) for some interesting complications with this dissociation using tasks that involve grasping. Their earlier study showed that body schema was immune to the illusion while the body image was not; the 2010 study, however, shows that the body schema can also be susceptible to the illusion. The researchers conclude that although there are still good reasons to distinguish between body image and body schema, "the motoric body representation is not intrinsically robust to bodily illusion" (211). For a more complete discussion and a dynamical approach that focuses more on the integrated functioning of body image and body schema than on dissociations, see Kammers (2008). Rohde et al. 2011, show a dissociation in the RHI between proprioceptive drift and the sense of ownership, where the former (but not the latter) can be initiated by vision alone, without tactile stimulation, as well as by short-term (but not by continuous exposure to) asynchronous tactile stimulation. Also see Marcel's work on postural illusions induced by muscle spindle vibration (see e.g., Marcel 2003). Initially, while conscious perception of the body succumbs to the illusion, movement is correct. Marcel suggests that the body schema is entirely responsive to the real and true determinate locational information of body parts and target, but body image is not. Marcel also shows, however, that if the signal to the subject to move is delayed, the longer the delay (up to around 9 secs), the more the movement is captured by the perceptual illusion. The illusory aspects of body image start to control movement and movement becomes progressively determined by the illusion. 
affective attitudes that can be made conscious, there is also a role for the body schema to play. Proprioceptive and kinaesthetic processes that feed body-schematic functions involved in motor control may also contribute to a pre-reflective self-awareness of my bodily posture and movement. Like the self-experience involved in Gibson's notion of ecological perception (which is an important factor in body-schematic control) this pre-reflective bodily experience remains tacit or recessive in my experience of the world. Accordingly, the distinction between body image and body schema doesn't carve things up in the same way as the distinction between conscious and non-conscious.

Berlucchi and Aglioti (2010) argue that the body image-body schema distinction does not adequately account for a certain category of body awareness, which is involved in body-directed action. Specifically, it doesn't account for the possible role of such phenomena as itch, pain, temperature sensations based on small-fibre afferent systems. They make a good point, which goes back to the original work on the body schema by Head and Holmes (1911/12). These researchers proposed two body schema systems - one for posture and the other for the localization of sensations on the body surface. It's also true, as Berlucchi and Aglioti point out, that these small-fibre systems are still intact in IW-his neuropathy affected only the large-fibres of the peripheral nervous system, which deliver information about proprioception and touch to the brain. Berlucchi and Aglioti then suggest, citing an unpublished study by Olausson, that this aspect of the body schema allows IW to find and scratch an itch, and that it thus has "the potential to guide motor actions, more specifically actions aimed at the body itself in absence of proprioception and fine touch." (28). Berlucchi and Aglioti fail to mention, however, that this is the case if IW knows where his limbs are by some other means, e.g., by vision. In other words, although IW has a pain, temperature, and itch map of his body that would allow him to find the point on his leg that needs attention, he lacks a proprioceptive body map that would tell him how that leg was postured. In some cases ${ }^{5}$ he would have to first locate the leg using vision; only then would he be able to go to the itch in a normal fashion, assuming he also knew the starting posture for the hand he needs to do the scratching. Moreover, the intact aspect of this body schema does not

5. There are some cases in which IW uses temperature as a cue for position sense. While sitting, for example, he rests his hands on his legs. He can tell from temperature cues, perhaps a literal part of what James calls 'warmth and intimacy', where his hands and his legs are. I thank Jonathan Cole some clarifications about IW on these various points. 
assist IW in guiding motor actions more generally than just, for example, finding the itch within a framework established by other means. The point is that these body schemas do not operate in an isolated fashion; they are normally quite integrated.

Berlucchi and Aglioti also cite the case of Schneider, the patient of Gelb and Goldstein made famous in phenomenological circles by MerleauPonty (1962). Here, I think, they get things wrong. They suggest that Schneider suffered from the lack of the "classic body schema"-i.e., the postural body schema - but was able to scratch an itch when necessary. Schneider's problems were much more complicated than IW; the latter does not have brain damage, where as Schneider's brain damage was likely quite serious given that it was from a wound from mine splinters to the head, although the full extent of his injuries remain unclear. ${ }^{6}$ Specifically, however, Schneider had trouble moving to order, or following instructions to make, what Goldstein called "abstract" movements. He had no trouble with "concrete" or habitual movements, like walking, sitting, maintaining posture or more generally with the automatic aspects of controlling movement. His trouble occurred when reflective regard to his own body parts were involved in the action. In other words, his problem was with body image rather than the body schema.

Coming back to the idea that the body image- -body schema distinction is not meant to explain everything, it is surprising that Berlucchi and Aglioti, after using the distinction to sort out issues pertaining to some aspects of bodily experience and pathology, go on to dismiss the distinction (which they call "vague"), joining a select tradition of theorists who like to throw up their hands in exasperated response to terminological confusion, the terms being so misused in different senses from one author to another. To throw up their hands, of course, they required their respective body schemas, and I'm not sure how they will do without them. They express some satisfaction, however, with a recent distinction by Carruthers $(2008 \mathrm{a} \& \mathrm{~b})$ between online and offline representations of the body. The distinction is similar to O'Shaughnessy's (1980) distinction between long-term body image (knowledge about stable aspects of one's body over time- - e.g., that I have two arms) and short-term body image (knowledge about current posture-e.g., where my arms are right now).

6. The complexity of Schneider's case is significant enough in terms of the neurological and behavioral data as it is presented by Gelb and Goldstein, and as discussed by Merleau-Ponty. Things are even more complicated if Goldenberg (2003) is correct about Schneider faking some of his symptoms. See Marotta and Behrmann (2004) for discussion. 
Once we consider action, however, the long-term (offline) and short-term (online) distinction, applies equally to the body schema, and indeed cuts across (but cannot replace, pace Berlucchi and Aglioti) the body imagebody schema distinction (see Tsakiris and Fotopoulo 2008 for discussion). Indeed, as Carruthers (personal correspondence) makes clear, the on-line/ off-line distinction was never intended as a replacement for the image/ schema distinction. The prior is meant as a distinction in representations (by their content) and the later a distinction in capacities that are not reducible to representations. Does calling body image and body schema 'body representations', as Berlucchi and Aglioti and others do, help to reduce vagueness? Recent work in philosophy of mind suggests that use of the term 'representation' in the cognitive sciences is growing more vague every day (see, e.g., Ramsey 2007; Gallagher 2008c; Hutto 2008).

Berlucchi and Aglioti, however, are more generally dissatisfied because we have no understanding of the neuroscience of a large number of bodyrelated pathologies: "virtually nothing is known about the derangements in brain organization leading to the depersonalization syndrome ... Cotard's syndrome ... body dysmorphic disorder ... the eating disorders anorexia nervosa and bulimia nervosa ... [and] body integrity disorder" (32). After spending most of their review going from one brain region to another summarizing what we know about their different roles, not only in regard to awareness of one's own body, but in regard to more general phenomena of body recognition (of others, in photographs, etc.), they go on to note the complexity and distributed nature of brain processes, and therefore the oversimplification involved in looking at the isolated functions of brain parts. What follows from this, they rightly suggest, is that we should not expect to find an isomorphism between brain processes representing the body and the body itself, despite some significant somatotopical elements. I'm in full agreement on this point, but it is not the case that such isomorphism is "implied by the body schema and body image concepts." To distinguish between body image and body schema, and to define them in terms of perceptual processes and motor control processes, suggests nothing about what the neurological factors underpinning these processes should look like. Indeed, the dynamical nature of body schematic processes involving interaction with the environment suggests that a narrow neurological account will never provide the full story.

As Berlucchi and Aglioti themselves realize, in regard to the 'body in the brain', neuroscience (at least using today's technologies) runs into some clear limitations. First, to be clear, since the body schema involves 
both central and peripheral nervous systems, there is certainly no hope in pointing to one or even a combination of brain areas to identify a body schema in the brain. ${ }^{7}$ Second, there is not, for example, simply one body map in the brain. Penfield's homunculus in the somatosensory cortex (S1) is probably the best known; but there are other such homunculi in motor cortex and in subcortical areas, and likely partial maps in a variety of brain areas that iterate and reciprocally project to one another and to a vast number of other areas that are not explicitly body areas. As Jaak Panksepp (1998) says of subcortical emotion areas, likewise, areas responsible for body schematic processes reiterate up, down, and across the brain in a complex dynamics. Just as recent reviews of the 'self in the brain' make clear that the self is seemingly everywhere and nowhere specific in the brain (see Gillihan and Farah 2005; Legrand and Ruby 2009; Vogeley and Gallagher 2011), something similar can be said of the body in the brain, which itself is not unrelated to those other iterated emotion processes and self processes. Third, processes related to body schema and body image are not simply interoceptive (including pain, temperature, itch, etc.), proprioceptive, and exteroceptive (including vision and haptic touch), but also what we might call alteroceptive, that is, they are intersubjective. Moreover, in this regard, alteroceptive processes are not likely to be limited to mirror neuron areas.

We need to take seriously the idea that bodily self-awareness is something that is complicated by the fact that the body is always dynamically coupled with the environment, and that the environment includes, not just physical factors, but also social, intersubjective factors. Social and cultural dimensions impinge upon the formation and maintenance of both body image and body-schematic processes. Accordingly, we should not think that the full account of bodily self-awareness can be given in terms of 'the body in the brain', since the body is more properly in-the-world, as phenomenologists like to say. All the more so, this idea has importance for understanding disruptions in bodily self-awareness in pathologies such as Depersonalization Syndrome, Cotard Delusion, Body Dysmorphic Disorder, the eating disorders Anorexia Nervosa and Bulimia Nervosa, Body Integrity Disorder, and so on.

7. This, I think, must qualify what some identify as the third Copernican revolution (after Copernicus and Kant) - the idea that the brain generates the body and the body has nothing to do with it (Halligan 2002, who attributes this "Copernican" insight to Melzack who writes: "you do not need the body to feel the body" since the body is built into the brain [cited in Halligan 2002, 262]). 


\section{Intersubjective and social factors}

Perhaps no one in the history of the use of the concepts of body image and body schema has done more damage in regard to the terminological confusion that continually motivates theorists like Berlucchi and Aglioti to throw up their hands and call for the abandonment of such concepts than Paul Schilder $(1923,1935)$. His very early use of the term 'body image' as equivalent to Head's term 'body schema' started a long tradition of interchangeable use and confusion. Although he claims to be in agreement with Head, Schilder equates the postural model with the final, conscious sensation of position. That is, he equates the body schema, as defined by Head, with the conscious image or representation of 'our own body which we form in our mind' (Schilder 1935, 11). He calls this representation a 'body image' or 'body schema'.

The image of the human body means the picture of our own body which we form in our mind, that is to say the way the body appears to ourselves ... We call it a schema of our body or bodily schema, or, following Head ... postural model of the body. The body schema is the tri-dimensional image everybody has about himself. We may call it 'body-image' (Schilder 1935, 11).

According to Schilder this is a conscious picture constructed not only from sensory impressions but also from unconscious libidinous elements.

Let me point another finger at Schilder, this time more positively to indicate something very important in his analysis. More than any other theorist, Schilder also highlights the social dimension that permeates our bodily movements and body awareness. For example, he makes this clear in his analysis of one of his paranoid schizophrenic patients who provided reports of her experience in delusional states in which she felt constantly violated by others - others would do things to her body with electricity; she focused on how others would interrupt her breathing, her food consumption, and simple movement. She felt her own shoulder move when she saw the other person's shoulder move. Schilder suggests that the patient "takes the postural models of others into her own" (215). The actions of others play out on her body image. Building on psychoanalytic theory, Schilder generalizes this idea.

I am of the opinion that the desire to be seen, to be looked at, is as inborn as the desire to see. There exists a deep community between one's own bodyimage and the body-image of others. In the construction of the body-image 
there is a continual testing to discover what could be incorporated in the body.... The body-image is a social phenomenon (217).

Schilder's thought here influences Merleau-Ponty's conceptions of body schema and social intercorporeity. The latter idea he summarizes in this way: "between this phenomenal body of mine, and that of another as I see it from the outside, there exists an internal relation which causes the other to appear as the completion of the system" (1962, 352; see 1968, 141, 143). Merleau-Ponty cites Schilder several times in his Phenomenology of Perception, and at one point attributes to Schilder a principle of the body schema that Merleau-Ponty extends to his concept of intercorporeity. "Schilder recognizes that such a complex is not the sum of its parts but is a new whole in relation to them" (Rojcewicz translation, 97, note 157). There is evidence, for example, that an agent's bodily movement in the presence of others or in contexts of social interaction is different and involves activation of different brain areas, than when the agent acts alone. The fact that social gaze can change how objects are manipulated by an agent (Becchio et al. 2007; 2008), for example, suggests differences in the body-schematic control of action depending on whether actions are performed in social as compared to non-social contexts. Experiments by Schilbach et al. (2011) show modulation of reaction times for reaching in contexts that involve social gaze (i.e., when another person is looking at the agent). This suggests that such modulatory effects of social gaze on action control may contribute to the coordination of one's actions with those of another agent (Schilbach et al., in press). In such cases, body-schematic processes are affected by very basic aspects of social contexts. It remains to be investigated how more complex contexts, and indeed, long-term cultural contexts, affect aspects of the body schema and via brain plasticity may make body-schematic processes specific for different cultures and intersubjective practices. ${ }^{8}$

This type of evidence may be taken to support a stronger claim that follows from Merleau-Ponty's notion of intercorporeity, namely, that the meaning of any individual's actions will be intertwined with the other's actions, and the co-constituted meaning will go beyond what either agent could contribute on his or her own. $1+1>2$. We might call this the tango

8. As Tony Marcel (personal correspondence) points out, one needs to be careful about differences between situations where there is a co-actor or an observer, and those without either present. In the latter cases the way in which the social domain enters into or affects body awareness and body control is quite different, and may involve a developmental rather than an occurrent account. 
principle. Just as when two people dance the tango something irreducible to either one emerges through their interaction, so in all strongly embodied social interaction, which is the most basic form of intersubjectivity (Gallagher 2001; 2005), what we have is not something that is simply additive. This holistic principle goes directly against the assumption of methodological individualism that informs most of the ongoing research about social cognition in psychology, philosophy, and neuroscience.

Methodological individualism: the assumption that social cognition depends on capabilities or mechanisms within an isolated individual, or on processes that take place inside an individual brain. (see Froese and Gallagher, under review).

Rehearsing the significant amount of evidence from developmental psychology, phenomenology, and dynamic systems modeling for the involvement of embodiment in social cognition is beyond the scope of this paper (see e.g., De Jaegher et al. 2010; Gallagher 2007; 2008a; Gallagher and Zahavi 2008; Ratcliffe 2007). It involves debates about theory of mind and alternatives to standard approaches to these questions. But let me summarize the essential points that are relevant to the questions that concern us here.

1. Developmental psychology shows us that from the very beginning our relations to others are primarily embodied sensory-motor engagements involving imitation, emotion, eye contact, gesture, and dynamical and affective attunement and interaction. These aspects are summarized under the headings of primary and secondary intersubjectivity in the literature (Trevarthen 1979; Trevarthen and Hubley 1978; Hobson 1993; Reddy 2008; see de Jaegher, Di Paulo, and Gallagher 2010). From birth the infant is pulled into these interactive processes. This can be seen in the very early behavior of the newborn. Infants from birth are capable of perceiving and imitating facial gestures presented by another (Meltzoff and Moore 1977; 1994). Importantly, this kind of imitation is not an automatic or mechanical procedure; Csibra and Gergely (2009) have shown, for example, that the infant is more likely to imitate only if the other person is attending to it.

2. These primary and secondary intersubjective processes are not left behind. Close analysis of facial expression, gesture and action in 
everyday contexts shows that as adults we continue to rely on embodied interactive abilities to understand the intentions and actions of others and to accomplish interactive tasks (Lindblom 2007; Lindblom and Ziemke 2007).

3. In just such strong embodied interaction, often in imitative behavior, and in the practical and culturally determined tasks of everyday life (contexts that characterize secondary intersubjectivity starting at the age of 1 year), we learn what action is, and what our own possibilities for action are, by engaging with others.

This kind of interaction, which is intersubjective, pragmatic, and normative, requires body schematic coordination, not just within the individual body, but synchronized in resonance with others, following either in-phase or phase-delayed behaviour, and in rhythmic co-variation of gestures, facial or vocal expressions (Fuchs and De Jaegher 2009; Gergely 2001). Continuous movements between synchronised, desynchronised and the states in-between, drive the process (De Jaegher 2008). Attunement, loss of attunement, and the process of re-establishing attunement maintain both differentiation and connection. With others, in such interactions, we learn what we can do and can't do, not just pragmatically in regard to skills that shape our body-schematic processes, but socially, and these various lessons inform our own self-conception, including the kind of evaluations that figure into the body image.

To be clear there are two claims here. First, that with respect to bodily awareness, and both body image and body schema, the intersubjective dimension is important. We can think here simply about social contexts that motivate self-consciousness about our bodily appearance, or about the deeper effects of culture on how we think about our bodies (see e.g., the discussion of anorexia, below), and even about how we move (see above). Second, following Merleau-Ponty, there is the stronger claim about intersubjectivity, namely the rejection of methodological individualism. To accept the first claim does not commit one to accept the second claim. If, however, understanding others is at least partially grounded in embodied social interactions, and interaction as well as body-schematic processes are more than what occurs in the individual's brain, as suggested above, approaches to social cognition that pursue methodological individualism are at least questionable. 


\section{Disorders of embodiment}

Coming back to those disorders that Berlucchi and Aglioti were so depressed about, I think one can get a good start at understanding them by using the body image-body schema distinction. This approach will set these various cases in an explanatory framework which will allow us to go in two different directions at once: first, pursuing the neuroscience as far as we can-something, however, that always ends up with an ambiguous and incomplete explanation, for reasons mentioned above; and second, abandoning the assumption of methodological individualism and taking seriously the idea that an analysis of individual brains will not give us the complete explanation. This involves acknowledging that the brain is embodied, that the body is always in an environment, that the environment is always social, as well as physical, and that the social aspects are simply not reducible to neurons firing in the brain, or beliefs and desires floating around in the mind. In this respect, too, I want to give up attempting to draw a line between the psychopathological and neuropathological. Some things clinically fall on one side rather than the other; but we might want to think of this as a continuum with most cases clustered around an ambiguous mid-point. Without trying to resolve this ambiguity, the following is an unsystematic look at some examples of how these various explanatory aspects might come together in the analysis of different kinds of disorders. ${ }^{9}$ The purpose of this section is threefold. First, to address the worries expressed by Berlucchi and Aglioti about the usefulness of the concepts of body image and body schema for the analysis of pathologies. Second, to reinforce the importance of the social dimension for these concepts. And third, to show that bodily self-awareness, and James' notions of warmth and intimacy can be disrupted in serious ways.

Body-schematic processes allow us to engage in world-directed activity without attending to our body. This body-in-action, or body-as-subject, remains in large degree experientially absent. That is, as we engage in the world, we do not explicitly attend to our body as such, or perceptually monitor its movements in any explicit way. Implicit in this experiential absence, however, is a sense of ownership - a pre-reflective sense that it is my body that is engaged in activity. ${ }^{10}$ If the body suddenly appears inad-

9. There is no hope of discussing all such disorders. Vignemont (2010) lists 41 different disorders of body awareness. A systematic discussion would have to address the majority of these.

10. The sense of ownership in this regard is self-specific, as defined by Legrand and Ruby 2009 and Christoff et al. 2011. 
equate to the task, or becomes fatigued, or ill, or in some social situations where the presence of another person motivates a self-conscious attitude, I may come to notice what had been this experiential absence, but now replaced by a situation in which the body is attended to, or even feels "in the way." In such cases, I may come to sense that my body has been functioning all along, beneath the threshold of explicit awareness. I may also come to experience this loss of experiential absence in other more positive experiences-e.g., in physical exercise, through self-inspection, looking in the mirror, or in sexual arousal. In any of these cases, one's body awareness normally includes a sense that the body in question is one's own.

Some pathological cases also involve this loss of experiential absence, but in a way that results in some alteration in the sense of ownership. The body is felt as something present, but more like an alien object than like the experiencing subject. In Depersonalization disorder patients may report a feeling of detachment from their body. In the Cotard Delusion some subjects claim they have died and that their body is decomposing. In such cases, however, there is not complete disownment since for such patients it remains their own body that they experience in this way. This abnormal presence of the body, however, is a curious form of self-consciousness. It alters the familiar sense of ownership for the body-as-subject, a minimal pre-reflective self-awareness that may be generated, in part, by aspects of body-schematic processes involved in movement and action, and which then forms an important element of the perceptual body image.

So far the phenomenology. Some theorists have suggested that these kinds of experiential disturbances in what James calls the 'warmth and intimacy' of the body, may be due to disturbances in affect, where partial or entire neural networks of affective processing may be destroyed (Gerrans 1999). With the loss of normal affect, the subject ceases to feel connected with her own body and comes to regard it as one object among others. Disorders in the affective aspect of the body image may also contribute to an account of disorders like anorexia nervosa. Although there is some general agreement that anorexia involves distortions of the body image (Bruch 1962), there is debate about whether the distortions are affective or perceptual in nature (Fernández et al. 1999; Uys and Wassenaar 1996; Hennighausen et al. 1999; Seeger et al. 2002). The neuroscience tells us that we should not see affect and perception as separate phenomena. Damasio (1994) and others have done much to disabuse us of the Cartesian view of affect as something that operates independently of cognitive function. Disruptions in affect likely involve disruptions in perceptual and cognitive/ 
conceptual dimensions, and vice versa. Lambie and Marcel (2002) note, however, that 'almost all the recent research [on emotion] concentrates on aspects of emotion experience that we would call self-focused rather than world-focused. Although Damasio (1994) includes mental images of what caused one's emotion, much of his account ... emphasizes experience of the body and of one's "mode of cognitive processing".' In this regard too, the full account is not indicated by calling emotions such as pride and shame 'self-conscious' or 'reflexive' without mentioning that the self-conscious or reflexive experience is motivated by others. Pride would be meaningless without its social meaning, and shame is obviously something that occurs before others (Sartre 2003; Zahavi 2010). More generally, however, as Schilder notes, "emotions are directed towards others. Emotions are always social" (218) - this is certainly the case with some emotions.

To say that Anorexia, and related disorders, involve the subject's body image, or an over-objectified bodily self-consciousness, is surely an incomplete story. Such disorders should be regarded as multidimensional (Legrand 2010) insofar as they also involve cultural and socially determined ideals of acceptable body shape. Susan Bordo (1993), for example, points to the importance of (1) religious and intellectual traditions that inform cultural attitudes about the body; (2) attitudes that involve gender and power in cultural expression and advertising; and (3) the issue of control in the life circumstances of the individual patient. A holistic view, then, recognizes that all such aspects-perceptual, affective, conceptual, cultural, and social—are mutually implicated in a disorder like anorexia. Others have surely made this case; my point is simply to indicate that we can best understand why these things manifest themselves in terms of the body image by recognizing the essential role of social interaction (including cultural, normative, and affective aspects) in the generation and maintenance of body image.

In addition, as we know from James, Damasio, and others, the whole body, and not just the brain, is implicated in the signature of emotion. Emotion involves not just a reiteration of subcortical patterns in cortical processes (Panksepp's idea), but extra-neural reiterations as well, in the same way that body schema and body image are both neural and extraneural. What gets expressed bodily is not just the outward expression of an emotion that is generated first in the brain; it may in fact run the other way: what happens in the brain may start as a reiteration of one's action attitude keyed to certain emotion affordances in the environment, including, of course other people. Reiterations that reach the cortex may be the 
mid-point of emotion formation rather than its beginning point; and the formation is often not a private matter, but very much an intersubjective one (see Gallagher 2008b, Ch. 9).

All these factors have an impact on the ambiguous alteration in the self-awareness involved in senses of ownership and agency or control with respect to the body. In anorexia, the idea that others are affectively experienced as "a violation of [the subject's] personal sphere" (Giordano, 2002, 4 ) and that anorexic subjects use their body to mediate their relations with others, motivates Legrand (2010) to suggest that "the perturbation of such bodily inter-subjectivity in anorexia reveals that, in normal cases too, the multidimensionality of one's bodily self-consciousness is not a private solipsistic matter" (734).

Depersonalization (see Michal et al. 2005; 2006), Cotard Delusion, and Anorexia involve, in different ways, disturbances in affect, intersubjective dynamics, and the ambiguous presence of the body as-object. In other disorders, more radical disruptions of the body image occur. Following stroke that affects the right parietal cortex, for example, the left side of the body can literally disappear from bodily self-awareness, with disruptions to the body image. In such cases of personal or unilateral neglect (e.g., Vallar 1993), there is neither a sense of presence, nor a sense of experiential absence, although, as noted above, in some cases there may be function of body schema. Other cases are complicated by paralysis and anosognosia (denial of the condition), and in cases of somatoparaphrenia the body appears to the patient to belong to someone else. Patients misidentify their arm or leg. They famously complain that there is a strange leg in their bed, or that they can't understand whose hand it is that is lying next to them, or they claim that it belongs to their husband or granddaughter (Feinberg 2001).

Katerina Fotopoulou (private correspondence) reports on a stroke patient who claims that her paralyzed and deafferented left arm belongs to her granddaughter. This is her response when she is asked about her arm and made to look at it. But when she is shown her full image in a mirror, and asked about her left arm as it appears in the mirror, she correctly identifies it as her own. When asked about her granddaughter's arm she looks down, directly at her left arm. Whenever she looks directly at her arm, she identifies it as her granddaughter's; whenever she looks at it in the mirror she identifies it as her own. The difference might be described as the difference between visual perception of the limb in the experiential canonical position (as we usually see our limbs) in the egocentric coordi- 
nates of our lived body (even if we visually focus on our left hand in this manner, it's position corresponds to its canonical body-schematic position that is ready for action), and visual perception of the limb in an experiential non-canonical position, in object-centered coordinates, which includes perception of the body in the mirror. The latter is closer to the way that others perceive our body, and the way we perceive the other's body.

I think there is a complicated story to tell here. We could likely appeal to the idea that different brain areas may be responsible for these two different kinds of perception, so one possible explanation is that the area of the parietal cortex, or the right posterior insula (see Baier \& Karnath 2008) damaged by stroke involves (or connects to) an area responsible for the canonical and coordinated body image/body schema, but not for our perception of the body in non-canonical (more objective) limb position, or the perception of other's bodies. ${ }^{11}$ It's a curious reversal. When the patient sees her own body as she usually sees it outside of the mirror, she attributes the body part to someone else; when she sees their own body as she sees others (and as others see her) she claim it as her own.

Schilder suggests that there is a "community ... between my image in the mirror and myself" which also implicates others (223). He offers a simple experiment to show this.

I sit about ten feet away from a mirror holding a pipe or a pencil in my hand and look into the mirror. I press my fingers tightly against the pipe and have a clear-cut feeling of pressure in my fingers. When I look intently at the image of my hand in the mirror I now feel clearly that the sensation of pressure is not only in my fingers in my own hand, but also in the hand which is twenty feet distant in the mirror. ... The feeling is therefore not only in my actual hand but also in the hand in the mirror. (223-334).

This proposed experiment comes just after Schilder had referenced Theodore Lipps' notion of Einfühlung, which is getting so much play today

11. Berlucci and Aglioti $(2010,30)$ summarize the state of the art in this respect: "Experimental evidence related to this question is contradictory. Recent fMRI studies by Hodzic et al. (2009) have reached the conclusion that EBA [extrastriate body area] is only involved in the analysis of body-related information but not in the assignment of body identity, insofar as it shows no differential activation to the presentation of unfamiliar or familiar bodies, including one's own body. Other studies have suggested that EBA is activated more by allocentric than egocentric views of body parts (Chan et al. 2004; Saxe et al. 2006), and more by one's own hand than by a stranger's hand (Myers and Sowden 2008).” There is some indirect evidence for precuneus and the posterior cingulate cortex being involved-Michielsen et al. 2010; or right superior temporal gyrus (STG) and the right superior occipital gyrus-Matthys et al. 2009) 
in the contemporary discussion of mirror neurons. I refrain from adding yet another solution to the overly long list of claims made about mirror neurons. Schilder highlights two things: (1) the cross modal influence of vision. In this regard, he suggests that "the experience of the [tactile] sensation in the mirror is as immediate and original as the experience in the real hand. It is at least very probably that part of these experiences are given when we see the bodies of others ..." (224). ${ }^{12}$ (2) Schilder insists, however, that this is not projection, and he appeals to experiments conducted by Landis on perception of emotion, to the effect that we can understand wholes much easier than we can understand isolated parts. Perhaps the image of the whole body in the mirror allows the stroke patient to attribute the limb to herself because she sees herself whole rather than in the canonical perspectival angle that for the most part is ignored as we act in the world (the normal experiential absence). Looking directly at her hand, from the first-person perspective of the agent, when in fact she cannot do anything with it, when it will not obey, failure of the sense of ownership does not seem so surprising; but looking in the mirror and seeing the hand in the context of the whole body, from a third-person perspective, and as someone else would see her, she clearly recognizes it as her own hand. Why, in the former case, the hand is attributed to someone else-a relative or friend or doctor-is a more difficult question to answer, and here if we followed Schilder we would likely take a psychoanalytic route.

Let me note, however, coming at all of this from a different angle, that recovery of function following stroke is facilitated by social context. Marcel (1992) has shown that degree of recovery is correlated to different intentions associated with semantic or pragmatic context, and social context (see Gallagher and Marcel 1999). In situations where the subject is instructed to carry out decontextualized, meaningless actions (e.g., in experimental setting, physical examination, or simple motor rehabilitation exercises), performance is poor, compared to situations that involve some kind of goal-oriented or meaningful action (e.g., drinking at a meal, washing dishes, writing to dictation). In these situations performance is better. But performance is best (sometimes approaching fluency) when actions are personally significant or derive their significance from the social and cultural setting (e.g., serving tea to friends, writing in a diary).

12. There is something to be said here in reference to the dominance of vision in the rubber hand illusion, which clearly involves the notion of the sense of ownership for a body part, in this case incorporating a limb that does not belong to one's body. 
My point here is simply that if social aspects of experience play some role in recovery, they may also play some role in how bodily self-awareness is shaped in the actual pathology.

A different sort of disruption of bodily self-awareness may be caused by lesions that result in Anarchic Hand Syndrome (AHS), a clinical disorder in which the patient's hand performs actions that are not under his/her control. The actions may appear to a third-person observer to be purposeful, although the patient describes the actions as involuntary. When AHS is associated with the split brain, it sometimes leads theorists to the radical interpretation that there are two independent centers of self-consciousness, one in each hemisphere, which are normally and pragmatically integrated via the corpus callosum, but which can be shown to be separate in the correct experimental setting. Yet AHS doesn't manifest with dissociated self-awareness. The sense of ownership (as part of the body image) is still intact-this is $m y$ arm that is acting up-while the sense of agency or control over my arm (generated by body-schematic processes) is disrupted. The movements may be accompanied by a feeling of foreignness and sometimes by the personification of the affected limb (Tow and Chua 1998). It is as if the arm belongs to someone else. But, in contrast to schizophrenic patients with delusions of control, AHS patients do not think someone else is performing the action; rather, it is "as if" someone else were controlling arm, or simply, that there is something wrong with their arm (Frith and Gallagher, 2002; Gallagher and Marcel, 1999; Della Sala, 2000).

In the disorders of the schizophrenia spectrum, the normally tacit aspects of automatic body-schematic processes are sometimes transformed into explicit aspects in a process that Louis Sass $(1992,2000)$ calls 'hyperreflexion'. A disruption in processes of action preparation (corresponding to neurological problems in body-schematic control) may disrupt the sense of agency for such action, and motivate a hyperreflexive focus on precisely aspects of movement that are normally tacit. Body-schematic functions are in most non-pathological cases, tacitly performed; as indicated above, the body-in-action tends to efface itself. Overly attending to our bodily movements makes them seem almost mechanical, and in some way alien. This sense of "being outside of the performance," makes one feel uneasy. Instead of simply driving, or walking, or breathing, for example, schizophrenic patients with delusions of control may start to think about the specific details of how they drive, or walk, or breathe. They experience and verbalize the body-schematic processes that are normally tacit and automatically functioning in activity. 
In Gallagher and Vaever (2004), for example, we reported on a young male patient who indicates he has to think about how to breathe; another patient reports that he has to "think about how to walk, how to move his legs, how fast to walk, whether he should stick to the right or the left on the sidewalk, whether to look up or down when walking." In such cases the patient lives in a way detached from his own lived performances. The bodily functions become mechanical. The agent takes himself or some aspect of himself as an object of awareness. Hyperreflexivity, Sass (1992; 2000) argues, means that the normally tacit, body-schematic processes of embodied activity can no longer perform the grounding, orienting, and constituting functions that they normally do. One patient states: "Sometimes I can't sense my own body. The sense of having a body ... Normally one does sense one's body." Another patient says: "I simply don't have any body sensation anymore, no feeling of the body still belonging to me. I sense that I'm sitting here, but it is an alien feeling." (Gross et al. 1987)

Tellingly, the same sense of alienation seems to permeate the subject's relations with others.

I don't say the right things, I am acting, it is a play, and I try so hard that I fall over.

I am not interested in other people, and I can't put myself in their place, it makes me a bad person.

I live in my head a lot, I drift away, thoughts come up, and I think of them, I am not listening, I just say yes and no. (Cited in Gallagher and Vaever 2004).

This suggests a possible correlation between problems with social interaction and motor or body-schematic problems. Just such problems exist in autistic children between ages 3 and 10 (see Damasio and Maurer, 1978; Vilensky, Damasio, and Maurer 1981) and even before that, in infants who are later diagnosed as autistic (Teitelbaum et al. 1998). If we take social interaction to be an embodied process, then problems that affect bodily movement, and bodily self-awareness would implicate difficulties in interaction at very basic levels.

This has been an incomplete and rather unsystematic review. One project would be to make it more systematic and to explore precisely the relations between body image, body schema, social interactions, cognition, affect, and neurological disruptions. Should such relations be categorized as merely correlational, or more strongly as causal; should they be regarded as constitutional for some of these pathologies? Clearly more empirical work is required to answer these questions. What I hope to have shown, 
however, or at least suggested, is (1) the minor premise: that body image and body schema may still be productive concepts in sorting out some of this; (2) the major premise: that our understanding of such pathologies will be incomplete if we look only at the neurology and ignore the phenomenology, especially the phenomenology of intersubjectivity; and (3) the conclusion: in regard to bodily self-awareness, we need a more holistic and integrative approach, one that recognizes the importance of social function as well as brain function, and accounts for how these two meet up in our bodies.

\section{James'solutions}

In conclusion, let me briefly bring these rather unsystematic considerations back to the problems that James was addressing in his Principles of Psychology. In describing the social self, James makes no reference to the role played by the body in our interactions with others. In passing, however, he hints at something we have just seen, specifically in regard to Anorexia. He suggests that if we were totally ignored by others, if we ran into complete disappointment in our relations with others, the "cruellest bodily tortures would be a relief; for these would make us feel that, however bad might be our plight, we had not sunk to such a depth as to be unworthy of attention at all" (294). He doesn't consider, however, that we might inflict those tortures on ourselves. In the less extreme dealings with normal everyday life, however, he does note that as we encounter different people we may act differently, and indeed, adopt different postures and gaits, swaggering "like a pirate," for example, among our "tough young friends" - something we can all relate to. There is, however, much more that we can say in regard to the material, the social, and the spiritual self.

James plants the spiritual self squarely in the bodily processes that generate a basic bodily self-consciousness - albeit the pre-reflective feeling of 'warmth and intimacy'. We've now seen, however, that this warmth and intimacy can go cold and for the most part is not an exclusive intimacy. Our bodily self-consciousness can turn from the warm glow of familiarity, to the flat affect of an alien object, in some cases due to purely contingent disruptions in brain process, and in other cases due to long-developing failures in intersubjective relations or the noxious effects of certain cultural forces. These disruptions and contortions of bodily self-awareness, 
as well as our normal everyday experiences, play out in terms that can be described in the vocabulary and grammar of body image and body schema, and in ways that reiterate in a complex neural and non-neural dynamics that involves dimensions of emotion, cognition, and our relations with others. If the warmth and intimacy of bodily self-awareness is the basis for our sense of personal identity, as James suggests, then we can also see how personal identity is not a purely autonomous or individual accomplishment; it takes shape in contexts that are always intersubjective and social, and is more vulnerable for it.

\section{REFERENCES}

Anema, Helen A.; van Zandvoort Martine J.E.; de Haan Edward H. F.; Kappelle L. Jaap; de Kort Paul L.M.; Jansen Ben P.W. \& Dijkerman H.Chris 2009: "A Double Dissociation between Somatosensory Processing for Perception and Action". Neuropsychologia 47, 1615-1620.

Baier, Bernhard \& Karnath, Hans-Otto 2008: "Tight Link Between Our Sense of Limb Ownership and Self-awareness of Actions". Stroke 39, 486-488.

Becchio, Cristina; Bertone, Cesare \& Castiello, Umberto 2008: "How the Gaze of Others Influences Object Processing". Trends in Cognitive Sciences 12(7), 254-258.

Becchio, Cristina; Pierno, Andrea; Mari, Morena; Lusher, Dean, \& Castiello, Umberto 2007: "Motor Contagion from Gaze: The Case of Autism". Brain 130(Pt 9), 2401-2411.

Berlucchi, Giovanni \& Aglioti, Salvatore M. 2010: "The Body in the Brain Revisited”. Experimental Brain Research 200, 25-35.

Bordo, Susan 1993: Unbearable Weight: Feminism, Western Culture, and the Body. Berkeley: University of California Press.

Bruch, Hilde 1962: "Perceptual and Conceptual Disturbances in Anorexia Nervosa”. Psychosomatic Medicine 24, 187-194.

Carruthers, Glenn 2008a: "Types of Body Representation and the Sense of Embodiment". Consciousness and Cognition 17, 1302-1316

- 2008b: "Reply to Tsakiris and Fotopoulou "Is My Body the Sum of Online and Offline Body Representations?". Consciousness and Cognition 17, 1321-1323.

Chan, Annie W.; Peelen, Marius V. \& Downing Paul E. 2004: "The Effect of Viewpoint on Body Representation in the Extrastriate Body Area". NeuroReport 15, 2407-2410. 
Christoff, Kalina; Cosmelli, Diego; Legrand, Dorothee \& Thompson, Evan 2011: "Specifying the Self for Cognitive Neuroscience". Trends in Cognitive Science 15(3), 104-112

Critchley, MacDonald 1979: "Corporeal Awareness: Body Image; Body Scheme". In: Critchley MacDonald (ed.), The Divine Banquet of the Brain. New York: Raven Press, 92-105.

Csibra, Gergely \& Gergely, György 2009: "Natural Pedagogy”. Trends in Cognitive Sciences 13, 148-53.

Damasio, Antonio 1994: Descartes Error: Emotion, Reason, and the Human Brain. New York: G. P. Putnam.

Damasio, Antonio R. \& Maurer, Ralph G. 1978: "A Neurological Model for Childhood Autism". Archives of Neurology 35, 777-86.

De Jaegher, Hanne 2009: "Social Understanding Through Direct Perception? Yes, by Interacting". Consciousness and Cognition 18, 535-542.

De Jaegher, Hanne; Di Paolo, Ezequiel \& Gallagher, Shaun 2010: "Does Social Interaction Constitute Social Cognition?”. Trends in Cognitive Sciences 14(10), 441-447.

Della Sala, Sergio 2000: "Anarchic Hand: The Syndrome of Disowned Actions". Creating Sparks: The BA Festival of Science. Available at www.creatingsparks.co.uk.

Dijkerman, H. Chris \& de Haan, Edward H. 2007: "Somatosensory Processes Subserving Perception and Action". Behavioral and Brain Science 2, 189-201; Discussion 201-239.

Farrer, Chloe; Franck, Nicolas; Georgieff, Nicolas; Frith, Chris D.; Decety, Jean \& Jeannerod, Marc 2003: "Modulating the Experience of Agency: A Positron Emission Tomography Study". NeuroImage 18, 324-333

Farrer, Chloe \& Frith, Chris D. 2002: "Experiencing Oneself vs. Another Person as Being the Cause of an Action: The Neural Correlates of the Experience of Agency". NeuroImage 15, 596-603.

Feinberg, Todd E. 2001: Altered Egos: How the Brain Creates the Self. Oxford: Oxford University Press.

Fernádez-Aranda, Fernando; Dahme, Bernhard \& Meermann, Rolf 1999: "Body Image in Eating Disorders and Analysis of its Relevance". Journal of Psychosomatic Research 47 (5), 419-28.

Frith, Chris D. \& Gallagher, Shaun 2002: "Models of the Pathological Mind". Journal of Consciousness Studies 9 (4), 57-80.

Froese, Tom \& Gallagher, Shaun (under review): "Being Together: Strong Interaction and Dynamic Systems".

Fuchs, Thomas \& De Jaegher, Hanne 2009: "Enactive Intersubjectivity: Participatory Sense-making and Mutual Incorporation". Phenomenology and the Cognitive Sciences 8, 465-486. 
Gallagher, Shaun 1986: "Body Image and Body Schema: A Conceptual Clarification". Journal of Mind and Behavior 7, 541-554.

- 2001: "The Practice of Mind: Theory, Simulation or Primary Interaction?". Journal of Consciousness Studies 8(5-7), 83-108.

- 2005: How the Body Shapes the Mind. Oxford: Oxford University Press.

- 2008a: "Inference or Interaction: Social Cognition without Precursors". Philosophical Explorations 11 (3), 163-73.

- 2008b: Brainstorming: Views and Interviews on the Mind. Exeter: Imprint Academic.

- 2008c: "Are Minimal Representations Still Representations?". International Journal of Philosophical Studies 16 (3), 351-69.

Gallagher, Shaun \& Cole, Jonathan 1995: "Body Schema and Body Image in a Deafferented Subject". Journal of Mind and Behavior 16, 369-390.

Gallagher, Shaun \& Marcel, Anthony J. 1999: "The Self in Contextualized Action". Journal of Consciousness Studies 6 (4), 4-30.

Gallagher, Shaun \& Væver, Mette 2004: "Disorders of Embodiment". In Jennifer Radden (ed.), The Philosophy of Psychiatry: A Companion. Oxford: Oxford University Press, 118-32.

Gallagher, Shaun and Zahavi, Dan 2008: The Phenomenological Mind. London: Routledge.

Gergely, György 2001: “The Obscure Object of Desire: 'Nearly, But Clearly Not, Like Me': Contingency Preference in Normal Children versus Children with Autism". Bulletin of the Menninger Clinic 65, 411-26.

Gerrans, Philip 1999: "Delusional Misidentification as Subpersonal Disintegration". The Monist 82(4), 590-608.

Gillihan Seth J. \& Farah Martha J. 2005: "Is Self Special? A Critical Review of Evidence from Experimental Psychology and Cognitive Neuroscience". Psychological Bulletin 131(1), 76-97.

Giordano, Simona 2002: "Qu'un Souffle de Vent: An Exploration of Anorexia Nervosa”. Medical Humanities 28, 3-8.

Goldenberg, Georg 2003: "Goldsten and Gelb’s case Schn.: A Classic Case in Neuropsychology?”. In: Chris Code, Claus W. Wellesch, Yves Loenette \& Andre R. Lecours (eds.), Classic Cases in Neuropsychology, vol. 2. Hove, New York: Psychology Press, 281-299.

Gross, Georg; Huber, Gerd; Klosterkötter, Joachim \& Linz, Maria 1987: Bonner Skala für die Beurteilung von Basissymptomen (BSABS: Bonn Scale for the Assessment of Basic Symptoms). Berlin: Springer Verlag.

Halligan, Peter W. 2002: "Phantom Limbs: The Body in Mind". Cognitive Neuropsychology 7 (3), 251-68.

Head, Henry \& Holmes, Gordon 1911/12: “Sensory Disturbances from Cerebral 
Lesion”. Brain 34,102-254.

Hennighausen, Klaus; Enkelmann, Dieter; Wewetzer, Christoph \& Remschmidt, Helmut 1999: "Body Image Distortion in Anorexia Nervosa: Is There Really a Perceptual Deficit?". European Child and Adolescent Psychiatry 68, $103 \mathrm{f}$.

Hobson, Peter 1993: "The Emotional Origins of Social Understanding". Philosophical Psychology 6, 227-249.

Hodzic, Amra; Kaas, Amanda; Muckli, Lars; Stirn, Aglaja \& Singer, Wolf 2009:

"Distinct Cortical Networks for the Detection and Identification of Human Body”. Neuroimage 45, 1264-1271.

Hutto, Dan 2008: Folk Psychological Narratives. The Sociocultural Basis of Understanding Reasons. Cambridge, MA: MIT Press.

James, William 1890: The Principles of Psychology (2 vols.). New York: Basic Books, 1950.

Kammers, Marjolein P. 2008: Bodies in the Brain: More than the Weighted Sum of their Parts. Enschede: Gildeprint.

Kammers, Marjolein P.; Kootker, Joyce A.; Hogendoorn, Hinze \& Dijkerman, H. Chris 2010: "How Many Motoric Body Representations Can We Grasp?". Experimental Brain Research 202, 203-212.

Kammers, Marjolein P.; de Vignemont, Frederique; Verhagen, Lennart \& Dijkerman, H.Chris 2009: "The Rubber Hand Illusion in Action". Neuropsychologia 47, 204-11.

Lambie, John A. \& Marcel, Anthony J. 2002: "Consciousness and Emotion Experience: A Theoretical Framework”. Psychological Review 109, 219-59.

Legrand, Dorothee 2010: "Subjective and Physical Dimensions of Bodily Selfconsciousness, and their Disintegration in Anorexia Nervosa". Neuropsychologia 48, 726-737.

Legrand Dorothee \& Ruby Perrine 2009: "What is Self Specific? A Theoretical Investigation and a Critical Review of Neuroimaging Results". Psychological Review 116 (1), 252-282.

Lindblom, Jessica 2007: Minding the Body_Interacting Socially through Embodied Action. Dissertation, University of Linköping and University of Skövde.

Lindblom, Jessica \& Ziemke, Tom 2008: "Interacting Socially through Embodied Action”. In: Francesca Morganti, Antonella Carassa \& Giuseppe Riva (eds.), Enacting Intersubjectivity: A Cognitive and Social Perspective on the Study of Interactions. Amsterdam, Netherlands: IOS Press, 49-63.

Marcel, Anthony J. 1992: "The Personal Level in Cognitive Rehabilitation”. In: N. Von Steinbuchel, E. Poppel \& D. von Cramon (eds.), Neuropsychological Rehabilitation. Berlin: Springer, 155-168.

Marotta, Jonathan J. \& Behrmann, Marlene 2004: „Patient Schn: Has Goldstein and Gelb's Case Withstood the Test of Time?“. Neuropsychologia 42, 633-638. 
Matthys, Koen; Smits, Marion; Van der Geest, Jos N.; Van der Lugt, Aad; Seurinck, Ruth; Stam, Henk J. \& Selles, Ruud W. 2009: "Mirror-induced Visual Illusion of Hand Movements: A Functional Magnetic Resonance Imaging Study”. Arch Phys Med Rehabil 90, 675-81.

Meltzoff, Andrew N. \& Moore, M.Keith 1977: "Imitation of Facial and Manual Gestures by Human Neonates". Science 198, 75-78.

Merleau-Ponty, Maurice 1962: Phenomenology of Perception. New York, NY: Routledge \& Kegan Paul.

Merleau-Ponty, Maurice 1968: The Visible and the Invisible. Evanston, IL: Northwestern University Press.

Michal, Matthias; Heidenreich, Thomas; Engelbach, Ute; Lenz, Cynthia; Overbeck, Gerd; Beutel, Manfred \& Grabhorn, Ralph 2006: "Depersonalization, Social Phobia and Shame" [in German]. Psychother Psychosom Med Psychol 56(9-10), 383-9.

Michal, Matthias; Kaufhold, Johannes; Grabhorn, Ralph; Krakow, Karsten; Overbeck, Gerd \& Heidenreich, Thomas 2005. „Depersonalization and Social Anxiety“. Journal of Nervous \& Mental Disease 193 (9), 629-632.

Michielsen, Marian E.; Smits, Marion; Ribbers, Gerard M.; Stam, Henk J.; van der Geest, J. N.; Bussmann, Jost \& Selles, Ruud W. 2010: "The Neuronal Correlates of Mirror Therapy: An fMRI study on Mirror Induced Visual Illusions in Patients with Stroke". J Neurol Neurosurg Psychiatry doi:10.1136/ jnnp.2009.194134

Milner, David \& Goodale, Melvyn A. 1995: The Visual Brain in Action. Oxford: Oxford University Press.

Myers, Andrew \& Sowden, Paul T. 2008: "Your Hand or Mine? The Extrastriate Body Area". Neuroimage 42, 1669-1677.

O'Shaughnessy, Brian 1980: The Will: Dual Aspect Theory. Cambridge: Cambridge University Press.

Paillard, Jacques 1999: "Body Schema and Body Image: A Double Dissociation in Deafferented Patients". In: Gantcho N. Gantchev, Shigemi Mori, \& Jean Massion (eds.), Motor Control, Today and Tomorrow. Bulgarian Academy of Sciences. Sofia: Academic Publishing House, 197-214.

Panksepp, Jaak 1998: Affective Neuroscience: The Foundations of Human and Animal Emotions. New York: Oxford University Press.

Poeck, Klaus \& Orgass, Bernt 1971: "The Concept of the Body Schema: A Critical Review and Some Experimental Results". Cortex 7, 254-277.

Ramsay, William 2007: Representation Reconsidered. Cambridge: Cambridge University Press.

Ratcliffe, Matthew 2007: Rethinking Commonsense Psychology: A Critique of Folk Psychology, Theory of Mind and Simulation. Basingstoke: Palgrave Macmillan. 
Reddy, Vasudevy 2008: How Infants Know Minds. Cambridge, MA: Harvard University Press

Ruby, Perrine \& Decety, Jean 2001: "Effect of Subjective Perspective Taking During Simulation of Action: A PET Investigation of Agency". Nature Neuroscience 4 (5), 546-50.

Sartre, Jean-Paul 2003: Being and Nothingness: An Essay in Phenomenological Ontology. Translated by H. E. Barnes, revised edition. London and New York: Routledge.

Sass, Louis 1998: "Schizophrenia, Self-consciousness and the Modern Mind". Journal of Consciousness Studies 5, 543-65.

- 2000: "Schizophrenia, Self-experience, and the so-called Negative Symptoms". In: Dan Zahavi (ed.), Exploring the Self. Amsterdam: John Benjamins, 140-182.

Saxe, Rebecca; Jamal, Nasheed \& Powell, Lindsey 2006: "My Body or Yours? The Effect of Visual Perspective on Cortical Body Representations". Cerebral Cortex 16, 178-182.

Schilbach, Leonhard; Eickhoff, Simon B.; Cieslik, Edna; Kuzmanovic, Bojana \& Vogeley, Kai (in press): "Social Gaze Influences Action Control in a Comparison Group, but not in Individuals with High-functioning Autism”. Autism Journal.

Schilbach, Leonhard; Eickhoff, Simon B.; Cieslik, Edna; Shah, Nadim J.; Fink, Gereon R. \& Vogeley, Kai 2011: "Eyes on Me: An fMRI Study of the Effects of Social Gaze on Action Control”. Social Cognitive Affective Neuroscience 6(4), 393-403.

Schilder, Paul 1923: Das Körperschema. Berlin, Springer.

- 1935: The Image and Appearance of the Human Body. London: Kegan, Paul, Trench, Trubner and Co.; New York: International University Press, 1950.

Seeger, Gert; Braus, Dieter F; Ruf, Matthias; Goldberger, Ursula \& Schmidt, Martin H. 2002: "Body Image Distortion Reveals Amygdala Activation in Patients with Anorexia Nervosa: A Functional Magnetic Resonance Imaging Study". Neuroscience Letters 326 (1), 25-28.

Spicker, Stuart F.T. 1975: "The Lived Body as Catalytic Agent: Reaction at the Interface of Medicine and Philosophy”. In: Hugo. R. Engelhardt \& Stuart F. Spicker (eds.), Evaluation and Explanation in the Biomedical Sciences. Dordrecht: Reidel Publishing Co.

Straus, Erwin 1967: “On Anosognosia”. In: Erwin Straus \& Richard Griffith (eds.), Phenomenology of Will and Action. Pittsburgh: Duquesne University Press, 103-125.

Tsakiris, Manos \& Fotopoulou, Aikaterini 2008: "Is my Body the Sum of Online and Offline Body-representations?”. Consciousness and Cognition 17, 13171320. 
Teitelbaum, Philip; Teitelbaum, Osnat; Nye, Jennifer; Fryman, Joshua \& Maure, Ralph G. 1998: "Movement Analysis in Infancy May Be Useful for Early Diagnosis of Autism”. PNAS 95, 13982-87.

Tow, Adela M. \& Chua, H.C. 1998: "The Alien Hand Sign: Case Report and Review of the Literature". Annals Academy of Medicine Singapore 27 (4), 582-85.

Trevarthen, C. B. 1979: "Communication and Cooperation in Early Infancy: A Description of Primary Intersubjectivity”. In: Margaret Bullowa (ed.), Before Speech. Cambridge: Cambridge University Press, 321-48.

Trevarthen, Colwyn \& Hubley, John. 1978: "Secondary Intersubjectivity: Confidence, Confiding and Acts of Meaning in the First Year". In: Andrew Lock (ed.), Action, Gesture and Symbol: The Emergence of Language. London: Academic Press, 183-229.

Uys, D. C. \& Wassenaar, D. R. 1996: "The Perceptual and Affective Components of Body Image Disturbances in Anorexic and Normal Females". South African Journal of Psychology 26 (4), 236-42.

Vallar, Giuseppe; Antonucci, Gabriella; Guariglia, Cecilia \& Pizzamiglio, Luigi 1993: "Deficits of Position Sense, Unilateral Neglect and Optokinetic Stimulation". Neuropsychologia 31, 1191-1200.

de Vignemont, Frederique 2010: "Body Image and Body Schema: Pros and Cons". Neuropsychologia 48, 669-680.

Vilensky, Joel A.; Damasio, Antonio R. \& Maurer, Ralph G. 1981: "Disturbances of Motility in Patients with Autistic Behavior: A Preliminary Analysis". Archives of Neurology 38, 646-49.

Vogeley, Kai \& Gallagher, Shaun 2011: "The Self in the Brain”. In: Shaun Gallagher (ed.), The Oxford Handbook of the Self. Oxford: Oxford University Press, 111-36.

Zahavi, Dan 2010: "Shame and the Exposed Self". In: Jonathan Webber (ed.), Reading Sartre: On Phenomenology and Existentialism. London: Routledge, 211-226. 